\title{
Anti-DENV-NS1 monoclonal antibody for the differential histopathological diagnosis of hemorrhagic fever caused by dengue
}

\author{
Cristina Takami Kanamura ${ }^{1} \cdot$ Roxane Maria Fontes Piazza $^{2} \cdot$ Silvia D.'Andretta Iglézias ${ }^{1} \cdot$ Cinthya Cirqueira Borges $^{1}$. \\ Marcelo Sansone ${ }^{1}$. Juliana Moutinho Polatto ${ }^{2}$. Dayane Lima Teixeira ${ }^{2} \cdot$ Miriam Aparecida da Silva $^{2}$. \\ Leticia Barboza Rocha ${ }^{2} \cdot J_{u l i a n a}$ Silva Nogueira ${ }^{3} \cdot$ Adriana Yurika Maeda $^{3} \cdot$ Fernanda Gisele da Silva Vasami $^{3}$
}

Received: 23 April 2021 / Accepted: 1 February 2022 / Published online: 7 February 2022

(c) The Author(s) under exclusive licence to Sociedade Brasileira de Microbiologia 2022

\begin{abstract}
Dengue is the most prevalent arboviral disease in humans in tropical and subtropical regions, especially in urban areas, and can cause major epidemics. Although a self-limiting illness, it may sometimes have serious hemorrhagic manifestations, and the outcome of dengue hemorrhagic fever has similar clinical manifestations as in other infections, which could result in death. Therefore, autopsy procedures are required under certain circumstances such as in hemorrhagic fevers, sometimes to confirm or to clarify the diagnosis that may have epidemiological consequences. Normally, the Immunohistochemistry Laboratory of the Pathology Center of Adolfo Lutz Institute receives autopsy samples from different hospitals in Sao Paulo State to confirm a previous diagnosis, especially hemorrhagic fever of infectious etiology. For this diagnosis, we have been using a mouse polyclonal antibody to dengue virus that often does not provide a clear conclusion, because of background staining or no relevant immunostaining, which hampers the histopathological analysis. Accordingly, in the present study, anti-DENV-NS1 monoclonal antibody $(4 \mathrm{H} 2)$ was tested to determine its accuracy in immunohistochemical analysis. Twentyfour autopsy cases of hemorrhagic febrile syndrome showing histopathological alterations compatible with dengue disease were studied: twenty cases were confirmed by RT-PCR for DENV-2 and in four by RT-PCR for yellow fever virus. Samples from autopsied cases of deaths caused by other infectious diseases (two meningitis $\mathrm{C}$ and two severe acute respiratory syndrome caused by influenza A H1N1) were included as negative control cases. Positive immunostaining for DENV-NS1 was detected in 16/20 (80\%) liver samples and 11/15 (73\%) spleen samples from autopsied hemorrhagic dengue patients, whereas the polyclonal antibody detected DENV antigens in 12/20 (60\%) liver and in 6/15 (40\%) spleen samples from the same cases. Positive results were not obtained with liver biopsy samples from yellow fever or Neisseria meningitides and Flu-A cases. $4 \mathrm{H} 2 \mathrm{mAb}$ recognizes the native protein of the four DENV serotypes in infected cells and did not cross-react with native ZIKV- or CHKV-infected cells by immunohistochemical assay, so it is a useful tool for differential histopathological conclusion of acute febrile hemorrhagic deaths.
\end{abstract}

Keywords Immunohistochemistry $\cdot$ Monoclonal antibody $\cdot$ Dengue $\cdot$ Deaths $\cdot$ Hemorrhagic febrile syndromes

\section{Introduction}

Responsible Editor:Mauricio Nogueira

Roxane Maria Fontes Piazza

roxane.piazza@butantan.gov.br

1 Núcleo de Anatomia Patológica Do Centro de Patologia, Instituto Adolfo Lutz, São Paulo, SP, Brazil

2 Laboratório de Bacteriologia, Instituto Butantan, São Paulo, SP, Brazil

3 Núcleo de Doenças de Transmissão Vetorial Do Centro de Virologia, Instituto Adolfo Lutz, São Paulo, SP, Brazil
Dengue fever is one of the most important mosquito-borne human diseases in humans worldwide, caused by one of the four dengue virus serotypes (DENV-1 to DENV-4) [1]. Infection with any of the DENV serotypes may be asymptomatic in the majority of cases or may result in a wide spectrum of clinical symptoms, ranging from dengue fever to the most severe forms of the disease, dengue hemorrhagic fever, or dengue shock syndrome, which includes coagulopathy, circulatory shock, hemorrhagic manifestations and organ 
dysfunction [2]. If not properly managed, mortality rates in severe dengue patients can be as high as $30 \%$ [3].

After a period of great epizooty due to yellow fever (YF) reported in Brazil's South and Southeast regions (2016-2018), the country faced an increase in fatal dengue cases caused mainly by DENV-2. Nevertheless, with simultaneous circulation of other microorganisms that may cause hemorrhagic fever such as Leptospira spp., Rickettsia ricketsii, hantavirus, and other arboviruses (YF virus, arenavirus), it is sometimes not possible to differentiate them in autopsy procedures [4].

In severe dengue cases, the liver is the most affected organ. The histopathological lesions are characterized by centrilobular necrosis with scarce Councilman bodies and mild microvesicular steatosis with little inflammation. In the spleen, there is a reduction in the splenic white pulp with lymphocytolysis; phagocytosis of these cells and red blood cells is also observed [5-8].

DENV nonstructural protein 1 (DENV-NS1) is the only viral protein secreted by infected cells, resulting in high blood concentrations patients with severe dengue disease. It plays a role in viral replication, immune evasion, and pathogenesis via activation of complement pathways [9]. NS1 can bind to the vascular endothelium where it initiates a series of events that increases the permeability of human endothelial cells, in addition to binding to circulating antibodies forming immunocomplexes [10]. These are deposited in renal tubules and, from then on, will not be detectable by serological tests. Studies suggest that the NS1 protein plays an important role in the phenomena observed in endothelial dysfunction during the evolution of the severe form of the disease (dengue hemorrhagic fever) [10]. DENV-NS1 can be detected in dengue patients for diagnostic purposes by an ELISA test in the beginning of the disease.

Immunohistochemistry has proven to be a useful tool in the diagnosis of infectious diseases in tissue samples. It is a very sensitive, safe, and specific diagnostic tool. Serological tests and blood RT-PCR are the common diagnostic tools for dengue. However, there are some situations that are necessary to confirm dengue in tissue samples, especially in hemorrhagic fevers in autopsy samples. Autopsy procedures can be mandatory under certain circumstances such as hemorrhagic fevers, sometimes to confirm or to clarify the diagnosis that may have epidemiological consequences. In Brazil, it is very important to detect YF, malaria, dengue hemorrhagic fever, rickettsiosis, and other emerging and reemerging diseases such as Zika and chikungunya fever viruses and arenaviruses. Dengue fever has emerged as a major global public health problem over the past four decades. Although the demonstration of dengue virus by means of biomolecular assays is widespread today, especially with RT-PCR, there may be some situations in which this approach cannot be used, such as with inadequate collection and/or sampling, misinformation, or lack of time due to rapid evolution to death. In these situations, the demonstration of the presence of viral antigens in tissue lesions by immunohistochemistry becomes crucial for the diagnostic conclusion either with a biopsy or at autopsy. Autopsy is important since the majority of cases are confirmed only by clinical physiognomies, and in an endemic country such as Brazil, the outcome of febrile hemorrhagic deaths can be due to other pathogens.

The Immunohistochemistry Laboratory (IHCL) of the Pathology Center of the Instituto Adolfo Lutz (PAC-IAL) routinely receives autopsy samples from different hospitals in Sao Paulo State to confirm a previous diagnosis, especially hemorrhagic fevers of infectious etiology. In the period covered by the present study (2018-2020), we have had a large number of deaths due to dengue hemorrhagic fever, caused mainly by DENV-2, which has been confirmed by biomolecular tests (RT-PCR) carried out by the Virology Center of the same institute (VC-IAL). Routinely, we have used a mouse polyclonal antibody to dengue virus [5] that often does not produce a straightforward outcome, because of background staining or no relevant immunostaining, which hampers histopathological analysis. To overcome this, we evaluated the DENV-NS1 monoclonal antibody 4H2 \{anti-DENV-NS1 mAb (4H2)\} [11]. 4H2 mAb belongs to the isotype IgG2a and binds to DENV-NS1 protein with a dissociation constant of $6.2 \times 10^{-8} \mathrm{M}$. The $\mathrm{mAb}$ recognizes in DENV2-NS1 the specific epitope ${ }^{127}$ ELHNQTFLIDGPETAEC $^{143}$ and recognizes DENV-1- to DENV-4-infected Vero cells, with no cross-reaction with Zika virus-infected Vero cells [11].

The results obtained showed that a new antibody alternative was established for dengue virus immunohistochemical (IHC) analysis performed on autopsy tissue samples of patients who died of hemorrhagic fever.

\section{Materials and methods}

\section{Casuistic}

From 2018 to 2020, twenty autopsy liver samples and thirteen spleen samples with confirmatory molecular tests for DENV-2, detected by RT-PCR in the liver and/or spleen, were selected. Additionally, other infectious disease cases were included as non-dengue controls. Confirmed samples \{by RT-PCR and IHC assay\} of yellow fever (YF, four cases), meningitis gen group $\mathrm{C}$ (Men-C, two cases), and severe acute respiratory syndrome due to influenza A H1N1 (SARS Flu-A H1N1, two cases) also were selected from the autopsy routine received at PAC-IAL from 2018 to 2020. All selected dengue cases showed histopathological lesions compatible with dengue in the liver and spleen, characterized by mild necrosis and apoptosis of isolated and 
Fig. 1 Major histological findings in acute dengue hemorrhagic fever: A mild necrosis and apoptosis (arrows) of isolated and sparse hepatocytes in the mediozonal region of the liver and $\mathbf{B}$ perifollicular reactivity in the spleen

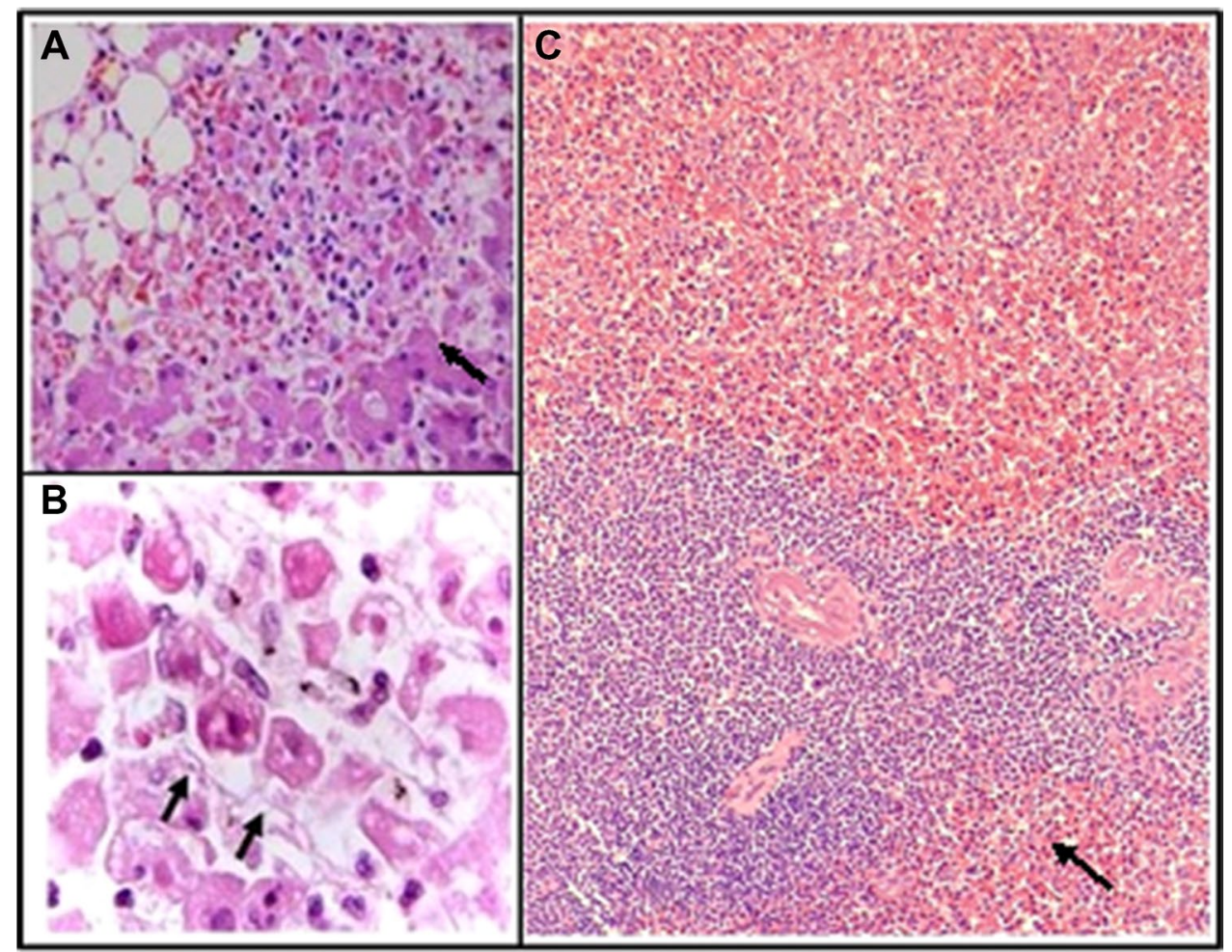

sparse hepatocytes in the mediozonal region of the liver and perifollicular reactivity in the spleen (Fig. 1).

For DENV-positive controls, pellets of cultured Vero cells infected with the four DENV types were produced [12], and cells fixed in $10 \%$ buffered formalin prior to paraffin embedding. To exclude any non-specific reactivity of the antibodies used in this study with other arboviruses currently of interest in Brazil, tests also included preparations of cultured Vero cells infected with native chikungunya virus (CHKV) and Zika virus (ZIKV).

Fig. 2 4H2 anti-DENV-NS1 monoclonal antibody purification. A ÄKTAprime profile using protein $\mathrm{G}$ affinity chromatography. B $12 \%$ SDS-PAGE profile with Coomassie blue staining

\section{RT-qPCR}

Total RNA was extracted from tissue samples (liver and spleen) using the QIAamp RNA Blood Mini Kit (Qiagen, Germany) following the manufacturer's instructions. RNA was submitted to one-step real-time reverse transcription quantitative polymerase chain reaction (RT-qPCR), probebased to detect and serotype DENV [13]. Samples were considered positive if cycle threshold (CT) was $\leq 36$. The threshold line was established right above the background signal and crossing the initial exponential phase for each serotype individually.
A

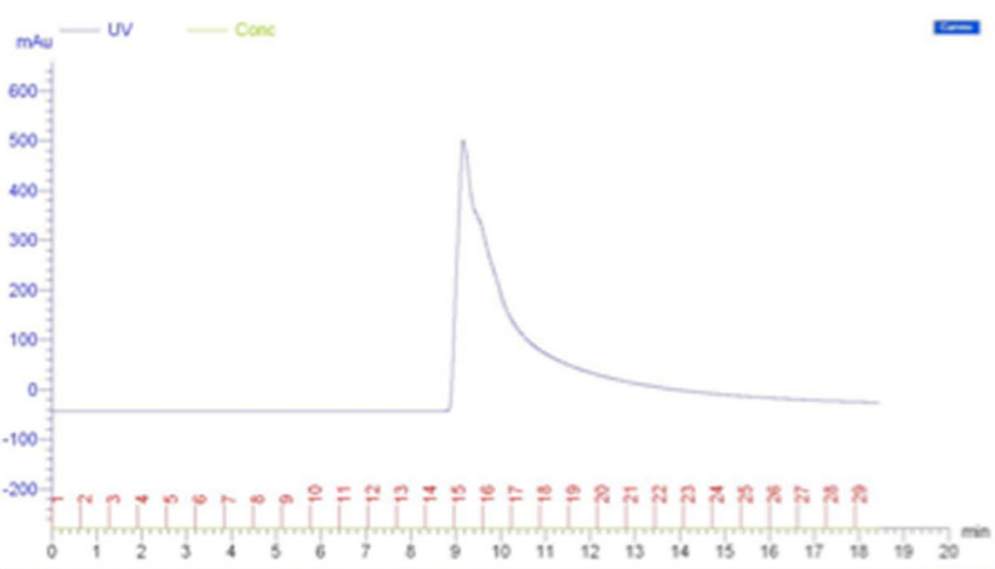

B

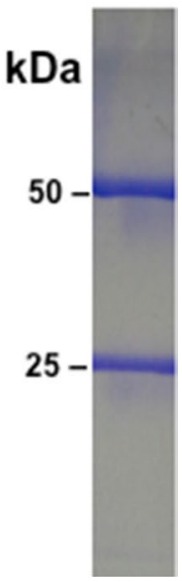


Fig. 3 Immunoreactivity of anti-DENV-NS1 mAb (4H2) in infected Vero cells visualized with alkaline phosphatase-conjugated secondary antibodies and Fast Red chromogen substrate: A DENV-1; B DENV-2; C DENV-3; D DENV-4

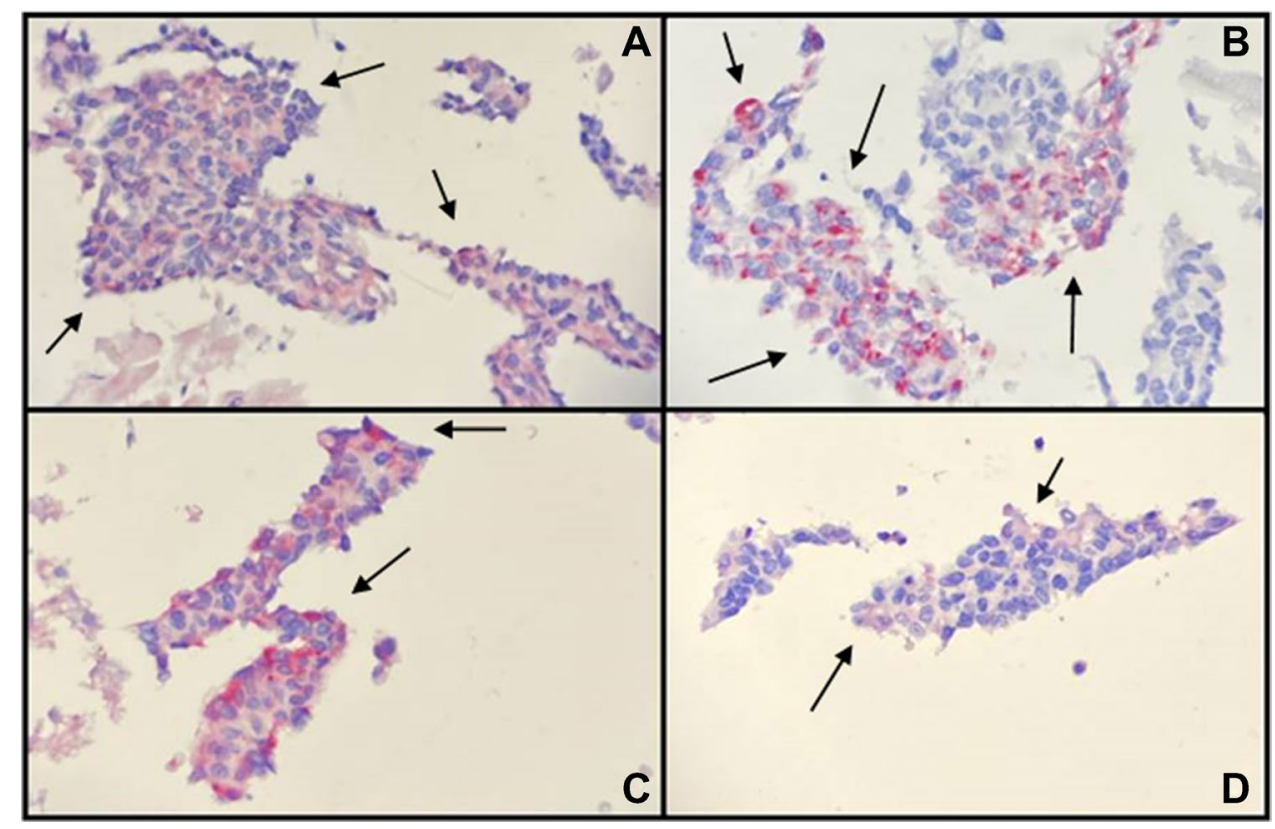

\section{Monoclonal antibody purification}

4H2 mAb-secreting cells, kept in liquid nitrogen, were thawed and expanded in RPMI 1640 medium supplemented with $10 \%$ fetal bovine serum at $37{ }^{\circ} \mathrm{C}$ and $5 \% \mathrm{CO}_{2}$. Hybridoma supernatants were collected, filtered $(0.45 \mu \mathrm{m})$ and purified by protein $\mathrm{G}$ affinity chromatography using ÄKTAprime (GE-Healthcare, Freiburg, Germany). MAb purity was determined by $12 \%$ sodium dodecyl sulfate-polyacrylamide gel electrophoresis (SDS-PAGE) with Coomassie blue R-250 staining.

\section{Immunohistochemistry}

Tissue fragments collected at the time of autopsy were routinely fixed in $10 \%$ buffered formalin and embedded in paraffin. Cell culture pellets were submitted to the same histological procedures. Immunohistochemistry procedures were performed on three micrometers 3 - $\mu$ m-thick tissue sections fixed on silane-treated slides. Antigen retrieval was performed at neutral pH (Reveal Decloaker, Biocare Medical, USA) by means of moist heat under pressure (Decloaking Chamber NxGen, Biocare Medical, USA). The sections were then incubated with protein-blocking solution (Background Punisher, Biocare Medical, USA), for $10 \mathrm{~min}$ at $37{ }^{\circ} \mathrm{C}$ and then by diluted primary antibodies in a humid chamber at $4{ }^{\circ} \mathrm{C}$ for $18 \mathrm{~h} .4 \mathrm{H} 2 \mathrm{mAb}$ (Butantan Institute) was diluted at 1:1,000 in diluent (1\% bovine serum albumin in $10 \mathrm{mM}$ phosphate-buffered saline (PBS), $\mathrm{pH}$ 7.4. The mouse polyclonal antibody (hyperimmune antiserum from ascitic fluid against four dengue strains, Instituto Evandro Chagas, Belem-Pará, Brazil) [5] was diluted at 1:10,000.
After this step, the slides were thoroughly washed in Tris-buffered saline (TBS) to proceed with amplification of the reaction through a system of polymers conjugated with secondary antibodies and alkaline phosphatase (MACH 4 Universal AP, Biocare Medical, USA), at $37{ }^{\circ} \mathrm{C}$ for $30 \mathrm{~min}$. After a new washing step in TBS, chromogenic substrate naphthol phosphate-Fast Red (Warp Red Chromogen, Biocare Medical, USA) was applied to the sections for 5 to $10 \mathrm{~min}$ at $37{ }^{\circ} \mathrm{C}$. The product of the enzyme-chromogenic substrate reaction was evidenced by the formation of a cherry-red precipitate. Finally, the slides were thoroughly washed in running and distilled water and subjected to counter-staining (light) with Mayer's hematoxylin, followed by dehydration and coverslipping with Entellan (Merck).

The evaluation of the reaction was carried out by light microscopy by the presence or absence of a colored immunoenzymatic reaction product provided by alkaline phosphatase and chromogenic substrate (cherry red color), as shown in Fig. 4a (positive control reaction).

\section{Results}

Before IHC assay, $4 \mathrm{H} 2 \mathrm{mAb}$ was purified by protein $\mathrm{G}$ affinity chromatography, and its purity was checked by SDS-PAGE, in which we observed both IgG chains (50 and $25 \mathrm{kDa}$ ) (Fig. 2). Previously, the reactivity of $4 \mathrm{H} 2 \mathrm{mAb}$ with the four DENV serotypes was verified by immunofluorescence of Vero cells infected with DENV-1 to DENV-4 [11]. Herein, as controls in IHC assays, we also confirmed the reactivity of this $\mathrm{mAb}$ in formalin-fixed and paraffin-embedded Vero cells infected with the four dengue serotypes. It 
Table 1 Samples used and results obtained in immunohistochemical study with anti-DENV-NS1 mAb (4H2) and mouse polyclonal antibody to DENV

\begin{tabular}{|c|c|c|c|c|c|}
\hline \# & Sex & Age (y) & RT-PCR & Anti-DENV-NS1 (4H2) & Polyclonal anti-DENV \\
\hline 1 & $\mathrm{~F}$ & 31 & DENV-2: liver, spleen & Negative & Negative \\
\hline 2 & $\mathrm{~F}$ & 36 & DENV-2: liver, spleen & Negative & Negative \\
\hline 3 & $\mathrm{~F}$ & 72 & DENV-2: liver, spleen & Positive: liver, spleen & Positive: liver, spleen \\
\hline 4 & $\mathrm{~F}$ & 80 & DENV-2: liver, spleen & Positive: liver, spleen & Positive: liver, spleen \\
\hline 5 & $\mathrm{~F}$ & 54 & DENV-2: liver, spleen & Positive: liver & Positive: liver \\
\hline 6 & $\mathrm{~F}$ & 60 & DENV-2: liver, spleen & Positive: liver & Negative \\
\hline 7 & $\mathrm{~F}$ & 26 & DENV-2: liver, spleen & Positive: liver, spleen & Positive: liver, spleen \\
\hline 8 & $\mathrm{~F}$ & 81 & DENV-2: liver, spleen & Negative & Negative \\
\hline 9 & M & 24 & DENV-2: liver, spleen & Positive: liver, spleen & Positive: liver, spleen \\
\hline 10 & M & 47 & DENV-2: liver, spleen & Positive: liver & Positive: liver \\
\hline 11 & M & 58 & DENV-2: liver, spleen & Positive: liver & Positive: liver \\
\hline 12 & $\mathrm{~F}$ & 28 & DENV-2: liver, spleen & Positive: liver, spleen & Negative \\
\hline 13 & $\mathrm{~F}$ & 39 & DENV-2: spleen & Negative & Negative \\
\hline 14 & $\mathrm{~F}$ & 44 & DENV-2: liver, spleen & Positive: liver, spleen & Negative \\
\hline 15 & $\mathrm{~F}$ & 72 & DENV-2: liver, spleen & Positive: liver, spleen & Negative \\
\hline 16 & M & 10 & DENV-2: liver, spleen & Positive: liver, spleen & Negative \\
\hline 17 & $\mathrm{~F}$ & 8 & DENV-2: spleen & Positive: liver, spleen & Positive: liver \\
\hline 18 & $\mathrm{~F}$ & 63 & DENV-2: liver, spleen & Positive: liver, spleen & Positive: liver, spleen \\
\hline 19 & M & 85 & DENV-2: liver & Positive: liver & Positive: liver \\
\hline 20 & M & 40 & DENV-2: liver, spleen & Positive: liver, spleen & Positive: liver, spleen \\
\hline 21 & M & 27 & YFV: liver & Negative & Negative \\
\hline 22 & M & 32 & YFV: liver & Negative & Negative \\
\hline 23 & M & 59 & YFV: liver, spleen & Negative & Negative \\
\hline 24 & M & 56 & YFV: liver & Negative & Negative \\
\hline 25 & $\mathrm{~F}$ & 4 & MEN-C: brain,lung,spleen & Negative & Negative \\
\hline 26 & $\mathrm{~F}$ & 9 & MEN-C: brain,liver,spleen & Negative & Negative \\
\hline 27 & M & 24 & FLU-A (H1N1pdm09):lung & Negative & Negative \\
\hline 28 & $\mathrm{~F}$ & 44 & FLU-A (H1N1pdm09):lung & Negative & Negative \\
\hline DENV-1-infected cultured cells & & & DENV-1 detectable & Positive & Positive \\
\hline DENV-2-infected cultured cells & & & DENV-2 detectable & Positive & Positive \\
\hline DENV-3-infected cultured cells & & & DENV-3 detectable & Positive & Positive \\
\hline DENV-4-infected cultured cells & & & DENV-4 detectable & Positive & Positive \\
\hline CHKV-infected cultured cells & & & CHKV detectable & Negative & Negative \\
\hline ZIKV-infected cultured cells & & & ZIKV detectable & Negative & Negative \\
\hline
\end{tabular}

In cases \# 5, 6,10,11, 15, and 19, spleen samples were not available for immunostaining assays

$D E N V$-1 dengue virus type $1 ; D E N V$-2 dengue virus type $2 ; D E N V$-3 dengue virus type $3 ; D E N V$-4 dengue virus type $4 ; Y F V$ yellow fever virus; $M E N-C$ Neisseria meningitides, Gen Group C; FLU-A influenza A virus, subtype H1N1 (pdm09)

was observed, in different patterns, that DENV-1 infected cells showed moderate reactivity, DENV-2- and DENV3 -infected cells demonstrated excellent reactivity, whereas DENV-4 showed light color reaction (Fig. 3).

Concerning the autopsy samples tested, among the 20 cases of dengue hemorrhagic fever confirmed by RT-PCR, positive immunostaining of the DENV-NS1 antigen revealed by $4 \mathrm{H} 2 \mathrm{mAb}$ was found in 16/20 (80\%) liver samples and in $11 / 15(73 \%)$ spleen samples, with histopathological lesions in the liver and/or spleen compatible with dengue. The mouse polyclonal antibody demonstrated antigen in $12 / 20$ $(60 \%)$ liver samples and in $6 / 15(40 \%)$ spleen samples. In five cases $(5 / 20,25 \%)$, dengue antigen demonstration in the spleen by immunohistochemistry was not possible because samples were not available (Table 1). Vero cells infected with $\mathrm{CHK}$ and $\mathrm{ZKV}$ virus did not react with $4 \mathrm{H} 2 \mathrm{mAb}$ nor with the polyclonal antibody as observed as well in YF, Men-C, and SARS Flu-A H1N1 samples, thus corroborating the specificity of anti-DENV-NS1 mAb (Table 1). 


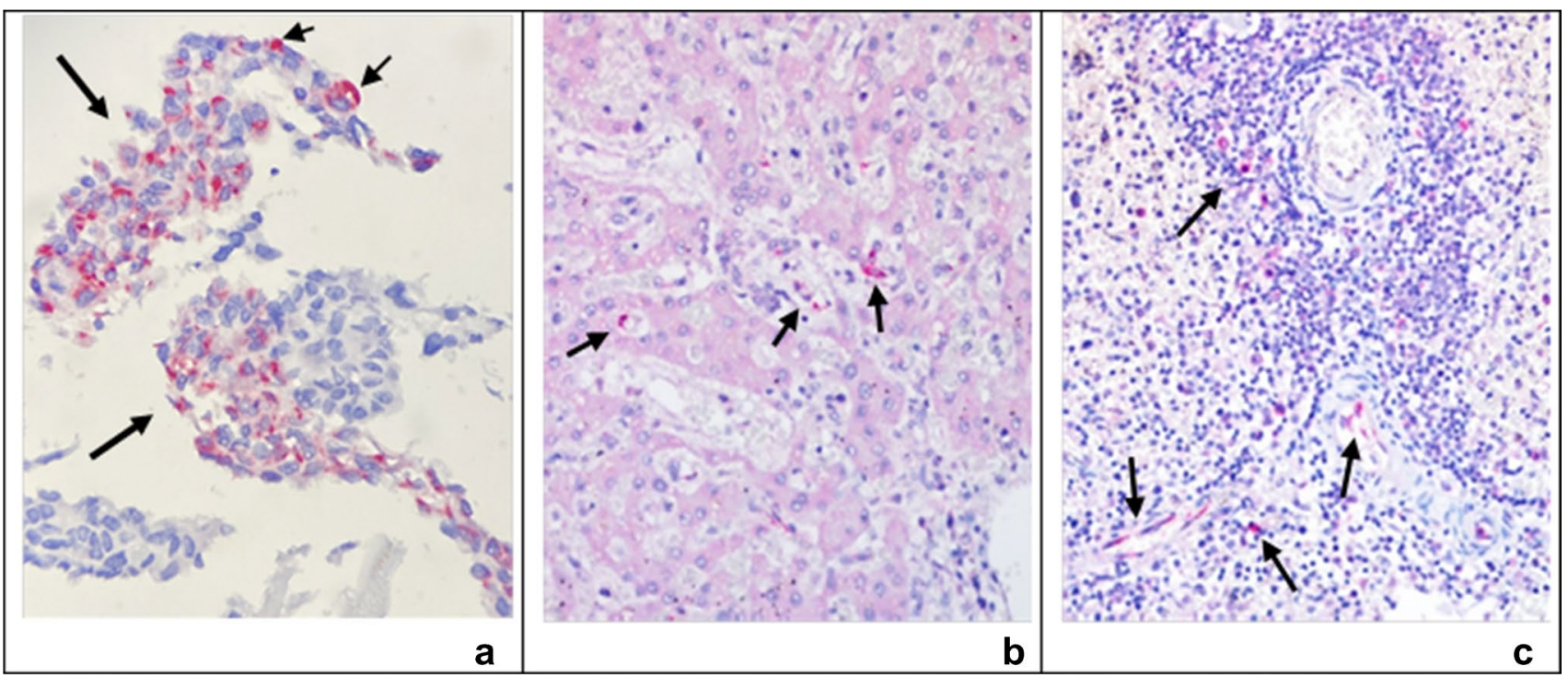

Fig. 4 Immunohistochemical reactions with anti-DENV-NS1 mAb (4H2), visualized with alkaline phosphatase-conjugated secondary antibodies and Fast Red chromogen (in red color), where the presence of the antigen was evidenced in a cultured Vero cells infected

Positive control using cultured cell infected with DENV-2 produced an intensely positive reaction with $4 \mathrm{H} 2 \mathrm{mAb}$ (Fig. 4a). The presence of the antigen was demonstrated in the liver in Kupffer cells and near the vascular endothelium (Fig. 4b), diffusely distributed in the liver parenchyma. No immunostaining was seen in hepatocytes. In the spleen, the antigen was detected in the cytoplasm of reactive lymphoid cells and macrophages, mainly perifollicular, and also in the endothelium of small vessels and centrilobular arterioles (Fig. 4c). The polyclonal antibody produced similar antigen immunolocalization but with lower intensity and in fewer cases. No positive results were found in YF liver samples (0/4), meningitis C (0/2), SARS Flu-A H1N1 (0/2), or in cultured cells infected by chikungunya fever virus (0/1) and Zika virus (0/1).

\section{Discussion}

Polyclonal dengue virus antibodies currently available in IHCL for IHC diagnosis do not perform well for the four dengue virus serotypes (DENV-1 to DENV-4). IHC analysis with anti-DENV-NS1 mAb in autopsied cases was positive in 16/20 liver samples (80\%) and in 11/15 (73\%) spleen samples of patients who died of dengue hemorrhagic fever, previously confirmed biomolecularly (DENV2-RT PCR). Immunostaining with the polyclonal antibody showed positivity in $12 / 20(60 \%)$ liver samples and in 6/15 (40\%) spleen samples. In five cases, IHC assay of spleen samples $(5 / 20$, $25 \%$ ) was not possible because fragments were not collected with DENV-2; b vascular endothelium and Kupffer cells in liver tissue; and $\mathbf{c}$ endothelium, macrophages, and reactive lymphoid cells in spleen tissue

or because material was inadequate probably due to bad tissue preservation (poor fixation or excessive exposure time in formalin). Although lower sensitivity and some background reactivity were seen in tests, this mouse polyclonal antibody is still a useful tool for initial screening. The NS1 antigen was detected in the liver only in Kupffer cells and endothelial cells (not in hepatocytes), and in the spleen, the presence of NS1 was demonstrated in reactive lymphoid cells, macrophages, and endothelial cells. Our results corroborate previous findings described by Puerta-Guardo et al. [10], showing that the damage caused by DENV-NS1 leads to endothelial hyperpermeability, thereby enabling $4 \mathrm{H} 2 \mathrm{mAb}$ to detect DENV-NS1 antigen in endothelial cells.

No positive results were obtained in liver samples of patients with YF (0/4), Men-C (0/2), or SARS Flu-A H1N1 $(0 / 2)$ or in cultured cells infected with CHKV $(0 / 1)$ or ZIKV $(0 / 1)$.

Because $4 \mathrm{H} 2 \mathrm{mAb}$ recognizes the native protein in IHC assays in Vero cells infected with the four DENV serotypes and since it did not cross-react with native ZIKV NS1 in infected Vero cells [11], we performed here IHC assays to determine the presence of NS1 protein from other dengue virus serotypes (DENV-1, DENV-3, and DENV-4) in experimentally infected cells, showing the sensitivity of this antibody in recognizing the four DENV serotypes. $4 \mathrm{H} 2 \mathrm{mAb}$ has been shown to be an excellent diagnostic tool for detecting DENV-2 antigen in formalin-fixed tissue samples and can be very useful in routine autopsy diagnostics, especially in the aforementioned epidemic outbreak of DENV-2. Further studies based on postmortem 
tissue samples in cases of other dengue serotypes should be carried out to evaluate the performance of this $4 \mathrm{H} 2$ antibody. Moreover, the crucial purpose of searching for better laboratory protocols is to increase the accuracy of differential diagnostics to benefit epidemiological surveillance actions.

Acknowledgements The authors are very grateful to Filipe Onishi Nagamori, Aparecida Andrade Pereira and Paloma Almeida Venancio Martins for technical assistance supported by GAPS/FESIMA/CCD/ SES (Health Secretariat of São Paulo State Government). Dr. A. Leyva (USA) provided English editing of the manuscript.

Author contribution SD'AI, RMFP, and CTK participated in the design of the study. CCB, MS, JMP, DLM, MAS, JSN, AYM, FGSV, and CTK carried out the experiments. SD'AI, CTK, and RMFP participated in data analysis. CTK and RMFP contributed reagents/materials/analysis tools; SD'AI, CTK, and RMFP participated in writing the manuscript. All authors read and approved the final manuscript.

Funding São Paulo Research Foundation (FAPESP - 2013/06589-6 to RMFP). RMFP is fellow of Conselho Nacional de Desenvolvimento Científico e Tecnológico. DLT was a junior recipient of a PIBIC/CNPq fellowship.

\section{Declarations}

Ethics approval This study was approved by the Adolfo Lutz Institute Scientific Committee (CTC 05-M/2020) and was conducted in accordance with ethical standards of the Research Ethics Committee of Plataforma Brasil (CAAE 36158820.2.0000.0059).

Conflict of interest The authors declare no conflict of interest. The funders had no role in the design of the study, in the collection, analyses or interpretation of the data, in the writing of the manuscript, or in the decision to publish the results.

\section{References}

1. Guzman MG, Halstead SB, Artsob H, Buchy P, Farrar J, Gubler DJ, Hunsperger E, Kroeger A, Margolis HS, Martínez E, Nathan MB, Pelegrino JL, Simmons C, Yoksan S, Peeling RW (2010) Dengue: a continuing global threat. Nat Rev Microbiol 8:S7S16. https://doi.org/10.1038/nrmicro246

2. World Health Organization (2009) Dengue guidelines for diagnosis, treatment, prevention and control: new edition. World Health Organization. https://apps.who.int/iris/handle/10665/ 44188. Accessed $20 \mathrm{Feb} 2021$

3. Ooi EE, Goh KT, Gubler DJ (2006) Dengue prevention and 35 years of vector control in Singapore. Emerg Infect Dis 12:887893. https://doi.org/10.3201/10.3201/eid1206.051210
4. Guarner J, Hale GL (2019) Four human diseases with significant public health impact caused by mosquito-borne flaviviruses: West Nile, Zika, dengue and yellow fever. Semin Diagn Pathol 36:170-176. https://doi.org/10.1053/j.semdp.2019.04.009

5. Hall WC, Crowell TP, Watts DM, Barros VLR, Kruger H, Pinheiro F, Peters CJ (1991) Demonstration of yellow fever and dengue antigens in formalin-fixed paraffin-embedded human liver by immunohistochemical analysis. Am J Trop Med Hyg 45:408-417

6. Jessie K, Fong MY, Devi S, Lam SK, Wong KT (2004) Localization of Dengue Virus in naturally infected human tissues, by immunohistochemistry and in situ hybridization. J Infet Dis 189:1411-1418

7. Martina BE, Koraka P, Osterhaus AD (2009) Dengue virus pathogenesis: an integrated view. Clin Microbiol Rev 22:564-580. https://doi.org/10.1128/CMR.00035-09

8. Povoa TF, Alves AM, Oliveira CA, Nuovo GJ, Chagas VL, Paes MV (2014) The pathology of severe dengue in multiple organs of human fatal cases: histopathology, ultrastructure and virus replication. PLoS ONE 9(4):e83386. https://doi.org/10.1371/journal. pone. 0083386

9. Chambers TJ, Hahn CS, Galler R, Rice CM (1990) Flavivirus genome organization, expression, and replication. Annu Rev Microbiol 44:649-688. https://doi.org/10.1146/annurev.mi.44. 100190.003245

10. Puerta-Guardo H, Glasner DR, Harris E (2016) Dengue virus NS1 disrupts the endothelial glycocalyx, leading to hyperpermeability. PLoS Pathog 12(7):e1005738. https://doi.org/10.1371/journ al.ppat.1005738

11. Rocha LB, Alves RPDS, Caetano BA, Pereira LR, Mitsunari T, Amorim JH, Polatto JM, Botosso VF, Gallina NMF, Palacios R, Precioso AR, Granato CFH, Oliveira DBL, Silveira VBD, Luz D, Ferreira LCS, Piazza RMF (2017) Epitope Sequences in dengue virus NS1 protein identified by monoclonal antibodies. Antibodies (Basel) 6(4):14. https://doi.org/10.3390/antib6040014

12. Martines RB, Bhatnagar J, de Oliveira Ramos AM, Davi HP, Iglezias SD, Kanamura CT, Keating MK, Hale G, Silva-Flannery L, Muehlenbachs A, Ritter J, Gary J, Rollin D, Goldsmith CS, Reagan-Steiner S, Ermias Y, Suzuki T, Luz KG, de Oliveira WK, Lanciotti R, Lambert A, Shieh WJ, Zaki SR (2016) Pathology of congenital Zika syndrome in Brazil: a case series. Lancet 388(10047):898-904. https://doi.org/10.1016/S0140-6736(16) 30883-2

13. Johnson BW, Russell BJ, Lanciotti RS (2005) Serotype-specific detection of dengue viruses in a fourplex real-time reverse transcriptase PCR assay. J Clin Microbiol 43(10):4977-83. https:// doi.org/10.1128/JCM.43.10.4977-4983.200

Publisher's note Springer Nature remains neutral with regard to jurisdictional claims in published maps and institutional affiliations. 